\title{
New Design Thoughts of Modern Children's Shoes
}

\author{
Sheng Sun \\ Jiang xi Institute of Fashion Technology \\ Nanchang, Jiang xi, China 330201
}

\begin{abstract}
At present, there are approximately 400 million children in China. Especially when the news of two-child policy comes out, China will be faced with a peak period of new-born children. With the rapid development of national economy, citizens' spiritual and material life standards are increasingly enhanced; meanwhile, they have a more high-level requirements and standards for their new-born generation. It is not a matter of eating one's fill and wearing warm clothes anymore. Apart from education, environment and nutrition, parents also attach much more attention on their children's shoes. Modern children's shoes design should meet children's physical and psychological demand; it is more important that it is supposed to match children's cultural connotation, modeling aesthetic and human engineering. Therefore, modern children's shoes design should be more subtle and deliberate than adults', which requires people to improve their innovative design thoughts and technological innovation.
\end{abstract}

Keywords-modern children's shoes; modeling aesthetic; innovative thoughts

\section{INTRODUCTION}

China responded to national one-child family planning policy since 1980s. At the moment, Chinese national conditions have changed and two-child police has been carried out. Although the policy has been implemented, the situation of single-family member in modern families will not be changed and children are still precious treasures in the whole society. In such a circumstance, children's products become the dynamic theme in market. Especially, the implementation of two-child policy is becoming the key design and development object of children's products companies. Since children's shoes are frequently used by them, from the perspective of shoe design and development, the author particularly investigates and surveys modern children's shoes market, deeply researches many brand children's shoes, and many research reports about children's shoes have been concluded. The author researches their psychological features from the perspective of children's genders and parents, children's shoes design modeling from the perspective of clothing, and approaches to select children's shoes. That the author researches is to help practitioners look up children's shoes design materials, and lead children's shoes to develop towards a more reasonable and suitable direction.

\section{A RESEARCH OF MODERN CHILDREN'S PHYSICAL AND PSYCHOLOGICAL FEATURES}

In China, people between 0 and 16 years old are generally called children, and there are four categories about children: toddler, kid, older kid and juvenile child. Generally, zerofour-year-olds are called toddler; five - seven-year-olds kids; eight - twelve-year-olds older kids and thirteen - sixteen-yearolds juvenile children. A child develops in matrix when it is an embryo in its fourth to eighth week, but it grows slowly in matrix. Children's feet start to grow from zero year old, and their grow rate speeds up at their one, rapidest at their one to two. In addition, girls develop earlier than boys. Some girls' feet are as big as boy's at their seven to nine. Generally speaking, the growth of feet is associated with their ages; the younger they are much growing space their feet will have.

There are many distinctions between modern and previous children's physiology and psychology. With the improvement of people's general living standards, children receive preliminary education from their infancy, and the environment and scientific nutrition ingestion have changed fundamentally; therefore, most modern children are robust, healthy and quickwitted. Their beauty-sought psychology has been beyond adults' imagination, and their imitation, thinking ability and aesthetic appeal is becoming younger and younger. It is apparent that previous children's shoes design thoughts cannot meet modern children's physical and psychological requirement, which is a new challenge for modern shoes designers; definitely, many previous children's shoes design thoughts can be referred to and extended.

If a designer wants to successfully design a pair of modern children's shoes, he/she must have a full understanding of modern children's physical and psychological features. The author believes that in modern children's shoes design, different ages should have different design; what's more, the designer should know the children's genders, growing environment and background when designing, observe boys' and girls' interests, aesthetic and activity features. Designers are also supposed to research children's requirements for shoes' functional and aesthetic demand, be familiar with trend and market conditions of modern children's shoes. In addition, children's parents' psychological and aesthetic preference cannot be ignored; they should design more children's shoes loved by parents. Meanwhile, different psychological features of boys and girls should be paid attention.

\section{MODELING DESIGN OF MODERN CHILDREN'S SHOES}

Modern clothing aesthetics is not just about clothing itself, but also its general design. Although shoes are the low-end work of human, it cannot be the fault of integral matching. Modern people have a more high-end aesthetic requirement, even to their surrounding objectives. Any objective of children 
will not be changed with subjective will power. Children are born to love beauty, and the modeling beauty is their first choice. When they are bought shoes, the color of shoes is the most important factor for them, then style and designs. A pair of shoes with beautiful modeling is always children's favorite. While adults usually value the quality of shoes; sometimes, they even argue with each other for their own opinion. Especially modern children, they dislike the same shoes of his/her peers; they like uniqueness. Traditional styles and color matching are not what they want anymore. They have advancing awareness, chase taste and innovation. With the influence of new era, young kids can quickly absorb emerging things; they are eager to possess a pair of shoes with modern cultural connotations and fashionable breath.

There is an old saying, "the most difficult thing in the world is not to accept new ideas, but to forget old ideas." Modern children's shoes designers should jump out of the circle obsolete ideas; they should not apply old clothing concepts to modern clothing design. Modern children's clothing should not only consider children's individual features, but also children's parents' aesthetic appreciation towards clothing. To some degree, children's aesthetic imperium is held by their parents. Designers should take the frontier position of fashion, step to the summit of new era, boldly innovate design thoughts and clear their mind. They should also deny themselves and design high-taste and advanced shoes that suit and are loved by children.

\section{OVERALl DESIGN OF MODERN CHILDREN'S SHOES}

Aiming at keeping sound in children's body and mind, the structural design of children's shoes is supposed to be cautious and meticulous in line with different ages, which directly relates to safety and comfort of children's shoes. Much disparity exists among foot shapes of children in different ages. In detail, younger children have chubby feet and a bit wider toes, and their feet will gradually be shaped; foot bones become stiff and elastic with their ages increasing.

Due to the simple thoughts of toddlers from 0 to 4 years old, their parents mainly take control of shoes they wear. Generally speaking, newly-born infants should wear socks or extremely soft cloth shoes. Boys and girls at this age have not many psychological requirements for styles, colors, patterns and functions, and the comfort and fitness of shoes can only be roughly estimated by their parents. Nevertheless, designers are required to pay attention to safe design of modern children's shoes especially for those infants who have not developed thermoregulation ability and are sensitive to external temperature. They are supposed to combine the children's characteristics at this age and adopt fiber materials like soft cottons having the property of mo isture absorption and heat preservation. In addition, micro-high and low-fronted or elastic-cord structures are suitable for toddlers instead of binding-type structure to avoid belts hurting children's feet. The toe caps must have the uniform width and be flat; shoe soles should be thin, light and with not bright colors. Pink is usually used for fear of causing bad effects on toddlers' eyes . Furthermore, shoes' decorative patterns should be harmonious, interesting and lively to meet infants' psychological demands and benefit their physical and psychological health so as to indicate specialty of infants. In conclusion, designers should comprehensively take into consideration of all those factors to satisfy parents' requirements.

Although little kids at the age of 5 to 7 have tender and delicate skins, their skeletons are increasingly stiffer. Those little friends, in their preprimary education phase, can speak and walk, and have strong imitative ability and a certain degree of aesthetic judgment. Since an initial shape of their friend circles and little society have been taken, they have certain observational ability and own opinions towards wearing shoes, and parents cannot completely control their attitudes upon shoes. Therefore, designers ought to correctly distinct the psychological demands for shoes of boys and girls, and make a difference between different gender's shoes in structural design, color matching and decorative patterns. In detail, boyoriented shoes should be designed with more aggressive structure and brighter colors such as army green, royalblue and yellow, etc. for them to ju mp actively; while girl-oriented shoes should be designed with elegant and light structure as well as warm color tones such as red, sky blue and yellow, etc. The most important of shoe designing for children at this age is ornamental parts which should be added with some high-tech decorative elements having the spirits of the times, such as magic lantern, dynamic animation and music devices and so on, except lots of "bionic" patterns.

Great increase in amount of exercise happens in older kids at the age of 8 to 12 . They have had relatively independent thoughts and formed their own perspectives of understanding objects. Large gap appears between the aesthetics of boys and girls and they have entirely different attitudes towards shoes. As they lay much emphasis on their personal images and tread on the heels of fashion, value other's evaluation to self as well, shoes designed for children at this age should not be extremely gorgeous and maverick. On the one hand, the styles of bigchildren shoes should be lively, active and novel combining with fashion elements; on the other hand, it is supposed to be taken into account that it is not beneficial for children at this age to show off. In addition, designers should take proper care of the combination and uniformity of shoes and school uniforms, and shoes must possess solid and firm structure, perfect overall appearance without over thinness, as well as strong-strength upper made of natural materials, skidresistance shoe soles that are also able to resist tearing and stretching. Moreover, ornamental parts should be designed as abstract images with properly exaggerated forms, and designers should seek interesting forms and styles to express the natural instincts of innocent and lively children at this age.

Children in 13 to 16 are also called "middle men" in shoemaking industry. They have experienced sudden and rapid psychological changes, and their skeletal muscles are closely similar with adults, particularly for girls who have grown relatively mature physiology and have sensitive and rich feelings. Besides, they attach much importance to their appearance, and clothes, shoes and hats have played important roles in prettifying their appearance. Comparing with boys, their fine and smooth thoughts decide that they care more of pursuit on perfection. Boys, generally with abstract thoughts and fondness of sports and intercourse, value their appearance as well and have stricter requirements for comfort and 
functions of shoes. The sizes and styles of teenagers' shoes are quite similar with adults' shoes, but great disparity still exists in design, colors and decorations. Therefore, teenagers' shoes should not be over mature and youth spirits of fashion, energy and health must be displayed. In addition, teenager-oriented shoes should have bright colors and good tastes, colorful but not complex, as well as be designed as light-footed styles with time's sense. Furthermore, health patterns with rich cultural connotation should be designed to decorate the shoes for passing social positive energy.

\section{SELECTION OF MODERN CHILDREN'S SHOE TREES}

The differences between shoe designing and costume designing lie in where costumes can have a certain degree of garment-tolerance, that is to say, a bit bigger or smaller sizes do not impact on their sales. While designing shoes requires designers to have good acquaintance with crural ergonomics. Furthermore, for meeting the requirements of children's development and health growth, children-oriented shoe designing needs to be attached more high-end attention, which is the most difficult part in costume selecting. Only constantly measuring and studying foot structure of children in different ages designers can make gradual progresses on the continuously developing children's costumes and shoes. In addition, any work of an excellent shoe designer must be fit for crural ergonomics.

A shoe tree plays a decisive role in shaping an elegant appearance and creating useful functions of a pair of shoes. It is required to lay stress on the growth and development of children's crural skeletons, joints and muscles in different ages while selecting suitable shoe trees for children's shoes; moreover, designers must, according to children's physiological characteristics in different ages, design shoe trees in consideration of the requirements of developing foot shapes and take comfort as the primary standard of selecting shoe trees. For example, shoe trees for younger children having bigger and chubby toes should be designed with a bit bigger width and girth and deeper in shoe lasts; while shoe trees for children in relatively older ages must be consistent with their foot shapes and enough space must be left in the front for actions, which must guarantee not only to easily put on an off and fit feet perfectly, but ankle not to be restricted and extruded when squatting. It is thus clear that fitness, comfort and safety must be ensured while selecting shoe trees of children's shoes.

\section{CONCLUSION}

Shoe designing for children in different ages has much in common in material application and decorative patterns but varies in styles, structures and color design. As a general rule, kinds of soft, breathable and lightweight natural materials such as cottons, fibers, silks and satins, etc. are very popular; moreover, "Bionic" patterns under a host of names are widely used among different ages of children's shoes designing. However, we cannot be stuck in limited elements without creativity. Following rapid development of economy and progress in science with each passing day, the rising of digital media greatly opens art's views of modern children, which motivates children's pursuit on dressing art and yearn for beauty. Therefore, shoe designing industry is facing up a severe challenge in this time under which circumstance, they must suffer the risk of being abandoned by the time without renewal in ideas and thoroughly reshaping thoughts and innovative thinking.

\section{REFERENCES}

[1] Tang Xiaozhou; Song Pengpeng. Humanization Design of Children's Casual Shoes [J]. Guangxi Journal of Light Industry, 2007-04-15

[2] Tang Xiaozhou. Study on Humanization Design for Children's Shoes [D]. Jiangnan University, 2007-05-01

[3] Xin Dongsheng. Exploration on Humanity Factors of Children's Shoes Design [D]. Hebei University, 2007-12-01

[4] Wang Baige; Liu Zijian. Discussion on Design Thoughts of Children's Leather Shoes [J]. Leather Science and Engineering, 009-06-28

[5] Ren Xiaobo. Analysis of Children's Shoes Design [J]. Chongqing Industry \& Trade Journal of Polytechnic, 2008-09-15

[6] Gao Haiyan. Brief Analysis of Humanization Design of Children's Shoes [J]. West Leather, 2008-10-20 